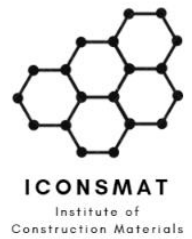

\title{
A methodology to virtualize technical engineering laboratories: MastrLAB-VR
}

\author{
Ivana Scidà ${ }^{1}$, Francesco Alotto ${ }^{2}$, Anna Osello ${ }^{3}$ \\ Department of Structural, Geotechnical and Building Engineering, Polytechnic of Turin, Turin, TO 10129 ITALY \\ 1 Phone: +39 329-1122342; e-mail: ivana.scida@polito.it \\ 2 Phone: +39 388-3493835; e-mail: francesco.alotto@polito.it \\ ${ }^{3}$ Full Professor; Phone: +39 335-1800784; e-mail: anna.osello@polito.it
}

\begin{abstract}
Due to the importance given today to innovation, the education sector is evolving thanks digital technologies. Virtual Reality (VR) can be a potential teaching tool offering many advantages in the field of training and education, as it allows to acquire theoretical knowledge and practical skills using an immersive experience in less time than the traditional educational process. These assumptions allow to lay the foundations for a new educational environment, involving and stimulating for students. Starting from the objective of strengthening the innovative teaching offer and the learning processes, the case study of the research concerns the digitalization of MastrLAB, High Quality Laboratory (HQL) belonging to the Department of Structural, Building and Geotechnical Engineering (DISEG) of the Polytechnic of Turin, a center specialized in experimental mechanical tests on traditional and innovative building materials and on the structures made with them. The MastrLAB-VR has been developed, a revolutionary innovative training tool designed with the aim of educating the class in total safety on the techniques of use of machinery, thus reducing the dangers arising from the performance of potentially dangerous activities. The virtual laboratory, dedicated to the students of the Building and Civil Engineering Courses of the Polytechnic of Turin, has been projected to simulate in an absolutely realistic way the experimental approach to the structural tests foreseen in their courses of study: from the tensile tests to the relaxation tests, from the steel qualification tests to the resilience tests on elements at environmental conditions or at characterizing temperatures. The research work proposes a methodology for the virtualization of technical laboratories through the application of Building Information Modelling (BIM), starting from the creation of a digital model. The process includes the creation of an independent application, which with Oculus Rift technology will allow the user to explore the environment and interact with objects through the use of joypads. The application has been tested in prototype way on volunteers, obtaining results related to the acquisition of the educational notions exposed in the experience through a virtual quiz with multiple answers, achieving an overall evaluation report. The results have shown that MastrLAB-VR is suitable for both beginners and experts and will be adopted experimentally for other laboratories of the University departments.
\end{abstract}

DOI: 10.36756/JCM.v2.3.3 @2021 Institute of Construction Materials

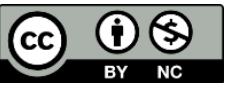

\section{Keywords}

Building Information Modelling; Digital learning; Education, Virtual laboratory, Virtual reality 


\section{Introduction}

The need to improve learning in schools is certainly a priority, given the rapid changes we are experiencing in our society. "It is widely believed that countries' social and economic well-being will depend to an ever greater extent on the quality of their citizens' education: the emergence of the socalled 'knowledge society', the transformation of information and the media, and increasing specialization on the part of organizations all call for high skill profiles and levels of knowledge. Today's education systems are required to be both effective and efficient, or in other words, to reach the goals set for them while making the best use of available resources" [1]. "The paradigms change: the classroom, understood as a physical place, gives way to dematerialization. New technologies allow a wider access to learning and the diffusion of the culture of innovation" [2]. Schools must not passively undergo these changes; on the other side, they must offer students and staff better tools to respond to new learning needs in a dynamic and innovative way.

In recent years, new education models based on innovative technologies such as Virtual/Augmented Reality are increasingly emerging. Many scholars have highlighted the benefits that VR brings to students who use it, declaring that it is a valuable tool especially in educational contexts.

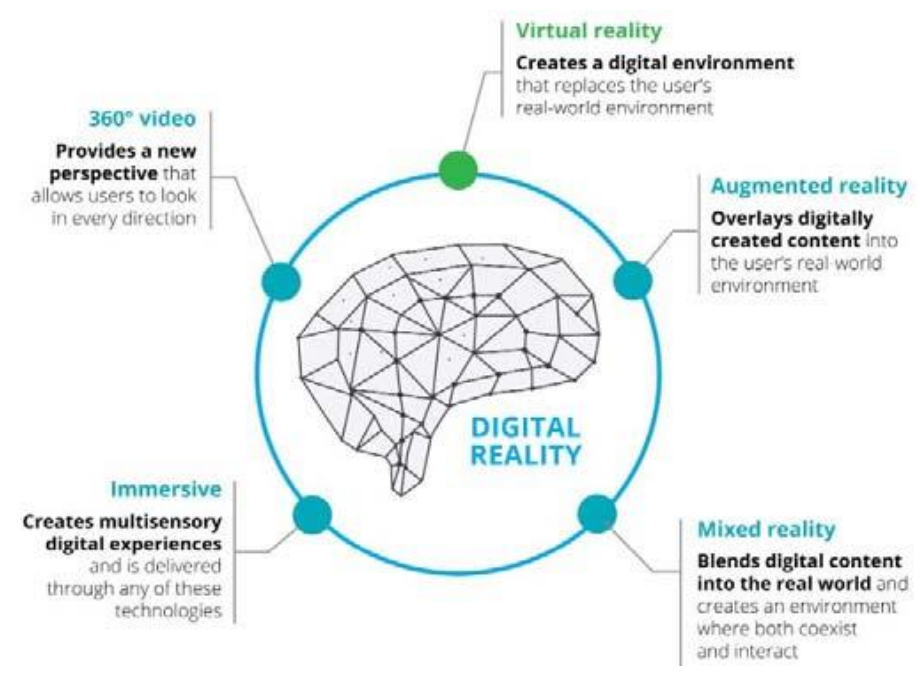

Figure 1 - Ecosystem of digital reality.

The immersive and multisensory activities that are carried out in VR, in fact, stimulate students' participation and attention compared to traditional lessons. VR immerses the user in a digitally recreated environment as if they were really inside, stimulating their sight and hearing. Within these contexts' students learn in a different way, becoming more passionate about the knowledge and activities proposed.

VR is a technological component of digital reality (Fig. 1) that can help solve real-world business problems and create competitive advantages [3]. The VR market is going through technological enhancement progress, with the aim of developing tools and frameworks that are increasingly ergonomic and adapted to the needs of the subject.

According to [14] "The Future of Immersive Experiences" dedicated to the Virtual and Augmented Reality in industry carried out by Gartner ${ }^{1}$ in $2022,70 \%$ of companies worldwide will have experimented immersive technologies with a use intended for customers or within the company, and $25 \%$ will use

\footnotetext{
${ }^{1}$ It is the world's leading research and advisory company. It equips business leaders with indispensable insights, advice and tools.
} 
them for production. In addition, IDC data [4] show that revenues for the Augmented and VR market at European level, between 2017 and 2022, will increase at an average annual growth rate of 74\%: total expenditure on AR and VR products and services will increase from \$1.06 billion in 2017 to $\$ 16.84$ billion in 2022. The education sector is expected to grow most through the development of laboratories and new fields of research (with a CAGR of $128 \%$ ). In fact, in the last few years there have been a lot of applications of VR in the educational field [5], the learning experience in a virtual world has several advantages:

- Virtual platforms and headsets are the new tools for inspiring creative learning;

- Education whose is not possible in reality, will be possible in VR;

- Virtual game-based experience increases students' motivation;

- Collaboration in VR classroom fosters social integration of learners;

- Learning is achieved by direct interaction, not by mouse clicks;

The results from the learning process are truly assessed [6]. A further advantage of VR is the possibility to involve at the same time almost all the sense organs, allowing a complete perceptive immersion of the subject in the learning context and to use most of the senses in collaborative, practical and active activities, allowing the demolition of the walls of the classroom [7]. In the educational field, the application of VR allows to perform in total safety operations that are typically considered dangerous in school contexts, such as the use of specific equipment in laboratories. Moreover, it is possible to introduce mechanics and dynamics of gamification of education allowing a more engaging and entertaining learning. Starting from the considerations previously described, MastrLAB-VR, a revolutionary innovative training tool designed for the laboratory MastrLAB ${ }^{3}$ of the Department of Structural and Geotechnical Engineering (DISEG) has been developed with the aim to safely train an entire class on the techniques of use of machinery through the immersive technology of VR. MastrLABVR is suitable for beginners and experts and will be adopted on an experimental basis in several laboratories of the University departments.

\section{Methodology}

In this article, a methodology for the virtualization of the educational and research laboratories of DISEG will be presented in support of didactic innovation. The study of this research is focused on the use of $\mathrm{VR}$, based on a process of digitization of building heritage that has as its starting point the BIM "is an emerging technology for building modelling, collaborative design, and integrated project delivery" [8]. The methodology (Fig. 2) that has been defined for this work is the following:

1. Data research in a traditional and innovative way

2. Documentation analysis

3. Architectural modelling of the laboratory

4. Machinery modelling

5. Creation of interactive virtual environments.

During the research phase, data were collected thanks to traditional surveys (geometric survey, functional survey, archive documents and Cad plans) and innovative surveys (Cloud of points, videos and photos at $360^{\circ}$ ), the latter allowed to obtain a quantity of information unachievable with traditional surveys. In the second phase, analyzing the documents, it became clear that other types of information were needed related to the conditions of the structure. After establishing the structure of the project

\footnotetext{
${ }^{2}$ It is the rate of return required for an investment to grow from its beginning balance to its ending balance.

${ }^{3}$ Laboratory that operates in the field of experimental scientific research on traditional and innovative building materials and structures made with these materials.
} 
folder (CDE) as required by the BS-PAS 1192 protocol in order to achieve good collaboration between users and proper coordination, the virtual model of the MastrLAB laboratory was created with Autodesk Revit 2018 software and the machines were modelled with Inventor 2018 software. In both models, all the alphanumeric and graphic information necessary to reach the research objective has been inserted. Fig. 3 represents interoperability between software used in this job.

Finally, to develop MastrLAB-VR, the digital model was exported in the interchange format. fbx. and imported into Autodesk $3 \mathrm{ds}$ Max software. After the materials were applied, the model was re-exported in fbx format, and imported into VR Unity 3D software to create the virtual environment with interactive content. Then the cameras, lights, etc. were set; and defined the operations, through the scripts, which were used to create the application, through the oculus Rift, a PC with a power that allows to manage VR games. The subject wearing the viewer and holding the joypads will be able to immerse himself in the virtual laboratory and through a virtual tour will be able to interact with the objects that are inside the virtual environment. The endpoint of our interoperability workflow is a 3D engine software, Unity3D. Unity VR lets target VR devices directly without any external plug-ins in projects. It provides a base API and feature set with compatibility for multiple devices and provides forward compatibility for future devices and software [9]. The VR system used is the Oculus Rift.

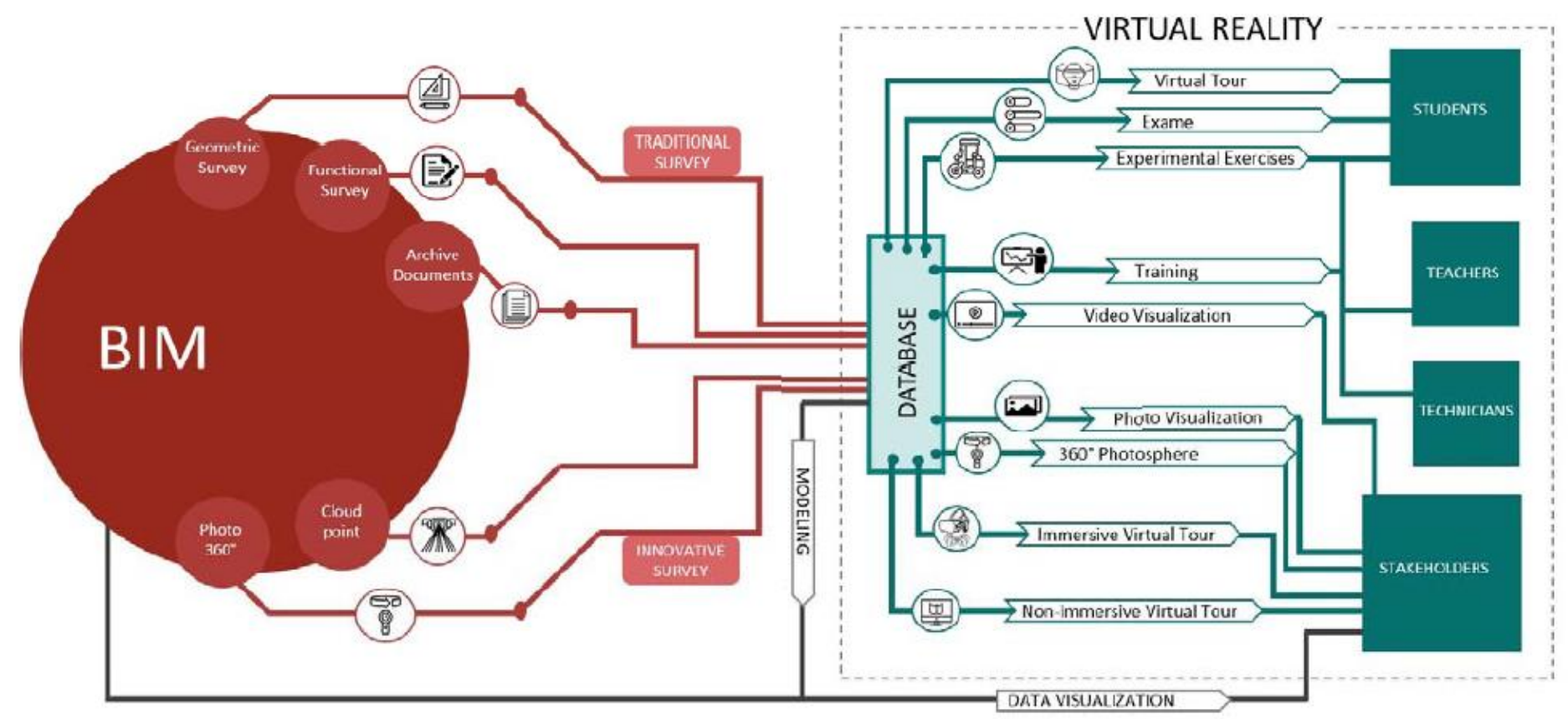

Figure 2 - Methodology schema 


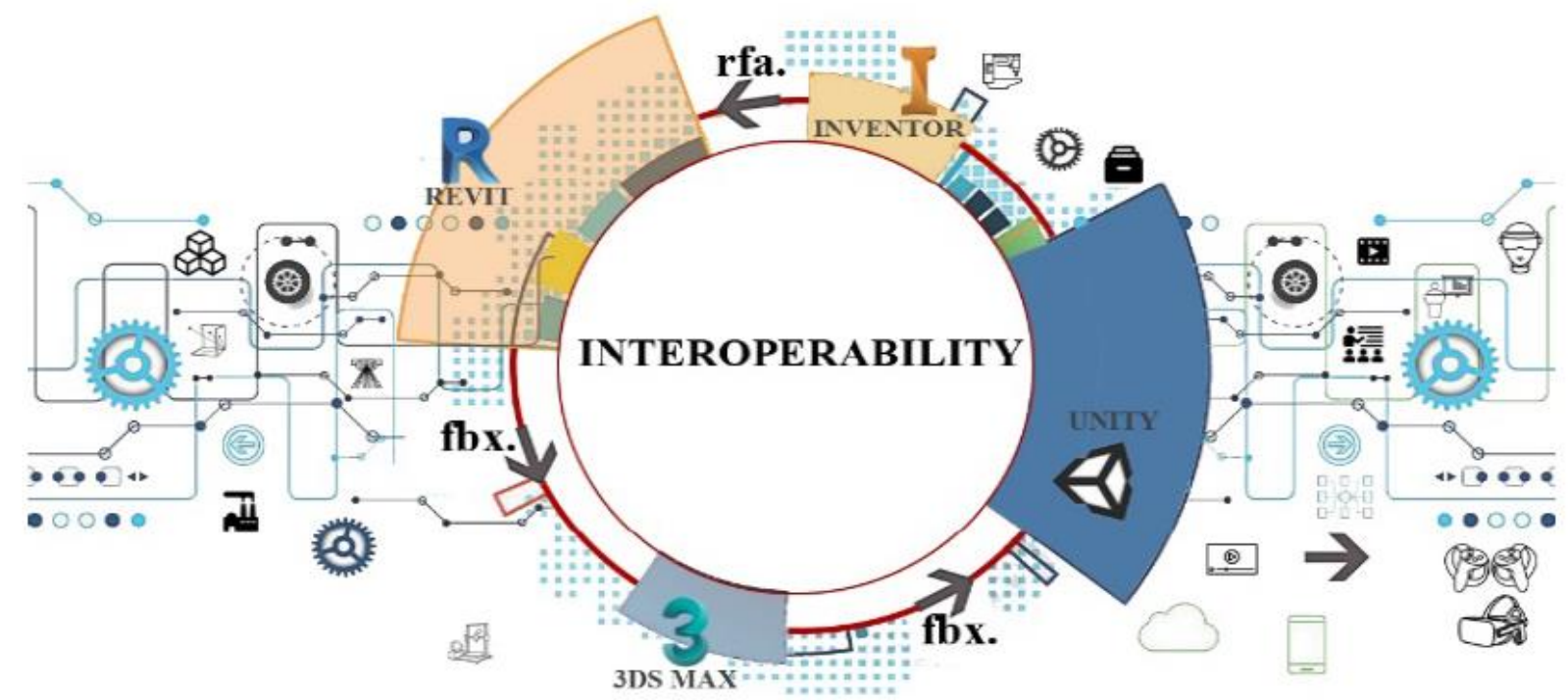

Figure 3 - Interoperability schema

Table 1 - Comparison between classical and VR-based learning workflow

\section{Classical learning limits $\quad$ VR based learning benefits}

Limited seats for larger classes and limited time

Mainly theoretical concepts with non-existent connection between theory and practice

Some laboratories practice cannot be conducted in front of students due to safety rules
Unlimited seats and time

Practice tasks linked to theory

All laboratory practices can be done in full safety environment

The preliminary stage of the process consisted of the creation of the virtual environment by assets import and corrections. As shown in Table I, through analysis on learning methods has been created a comparative table among classical laboratory learning workflow and the one assisted by VR.

As first step, different interviews have been done among laboratory stakeholders in order to formalize the actual learning system that occurs to explain mechanical process in laboratory. With the creation of a VR system, most of problems can be overlapped. Fig. 4 represents the system architecture, whose creation has been inspired the needs that have been underline above. 


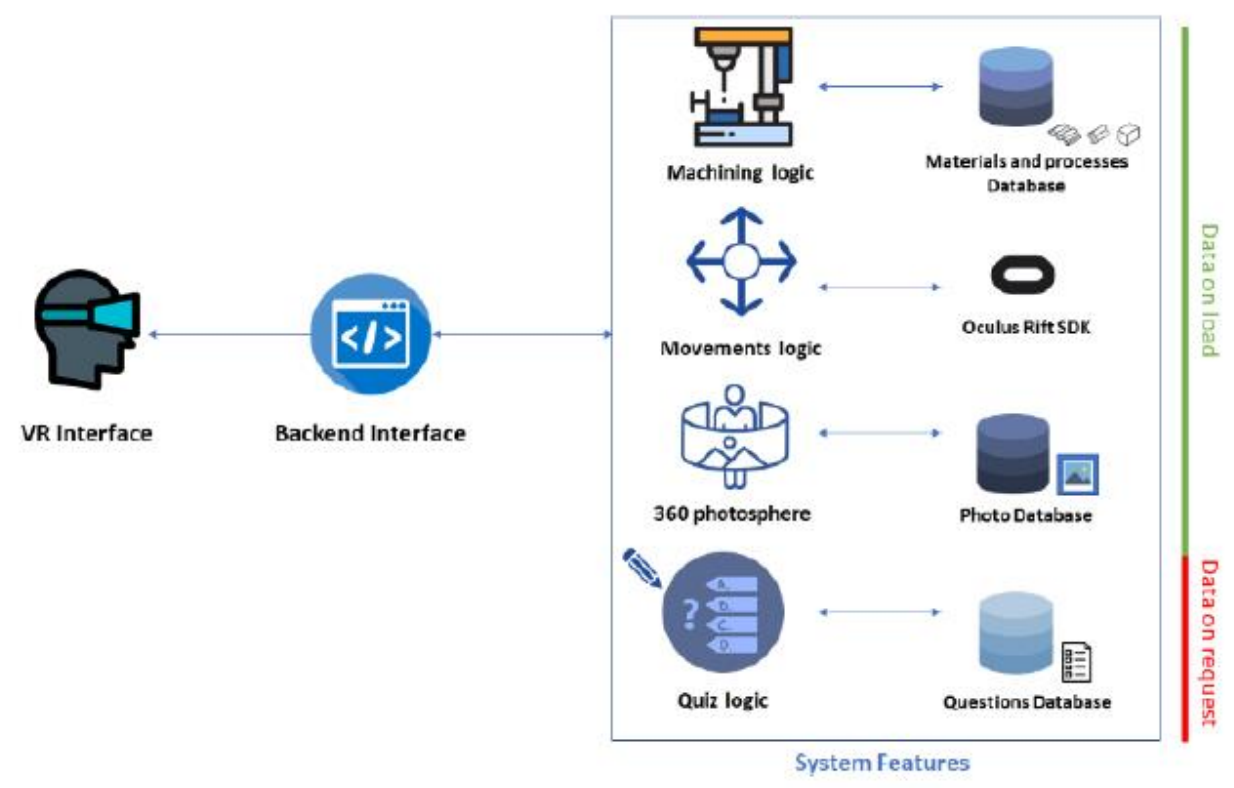

Figure 4 - System architecture

The endpoint on which the user can interact with the system is the VR Interface. The 3D model of the laboratory is visualized inside the VR device and the user can interact with through different triggers such as virtual buttons. The VR software is maintained by a Backend Interface, programmed to allow communication between graphic and logics. The Backend Interface component is the heart of the system and allows to recall data from the various satellites.

Two kinds of data have been treated:

- Data on load: necessary for the software working, they will be load at the start phase of the system.

- Data on request: loaded when a trigger requests them and are useful to perform additional operations.

The different logics inside the system enable different actions on the 3D models loaded.

The Machining Logic is the interface necessary to load the machines logic and the information related to various equipment. It is based on a database containing in json format the description of the machine and the list of operations that it can perform, linked to corresponding Unity Animation. Furthermore, there is the material list, containing data about mechanical parameters of different specimens. The Movements Logic is necessary for mapping real movements with virtual ones. It is performed by using the Oculus Rift SDK that proposes open APIs to manage the VR hardware.

Another feature that has been added is the $360^{\circ}$ Photosphere. Photospheres are photos on $360^{\circ}$; in this case, they show the real laboratory and are placed inside the virtual model in specific points to allow user to visualize the real environment inside the virtual one. Different triggers have been loaded in various positions inside the lab map. By crossing them, the 360 Photosphere logic loads the corresponding 360 photo of the surrounding environment allowing user to look at the real laboratory. This complex framework has been developed with the main goal of achieving consents between students and professionals. Three main aspects have been carried on achieving the results proposed: 
- Virtual involvement in using laboratory equipment

- Virtual experimentation in laboratory

- Verification of knowledge.

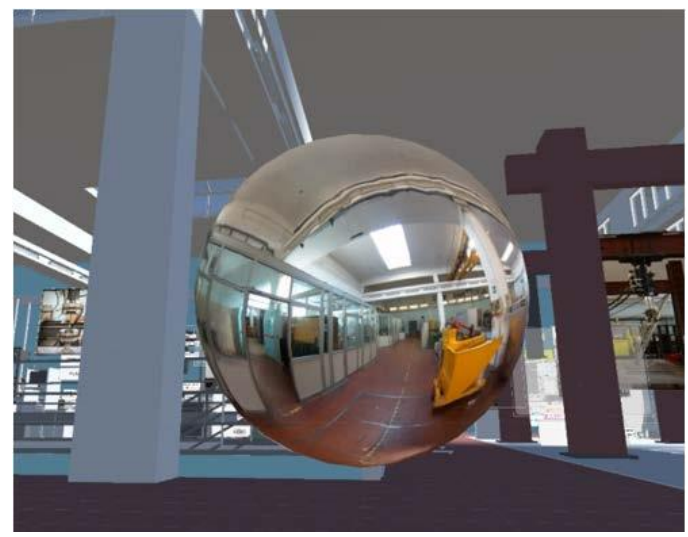

Figure 5 - 360 photosphere

To increase the involvement of users during the virtual experience, the system provides a complex integration of Oculus Rift Controller to simulate the real technical laboratory activities. In fact, the oculus rift controller allows, through the sensors installed, the virtual simulation of human hands gestures [10]. The controller mediation of real human hands movements has allowed developing better the sense of use linked to the manipulation of virtual laboratory tools.

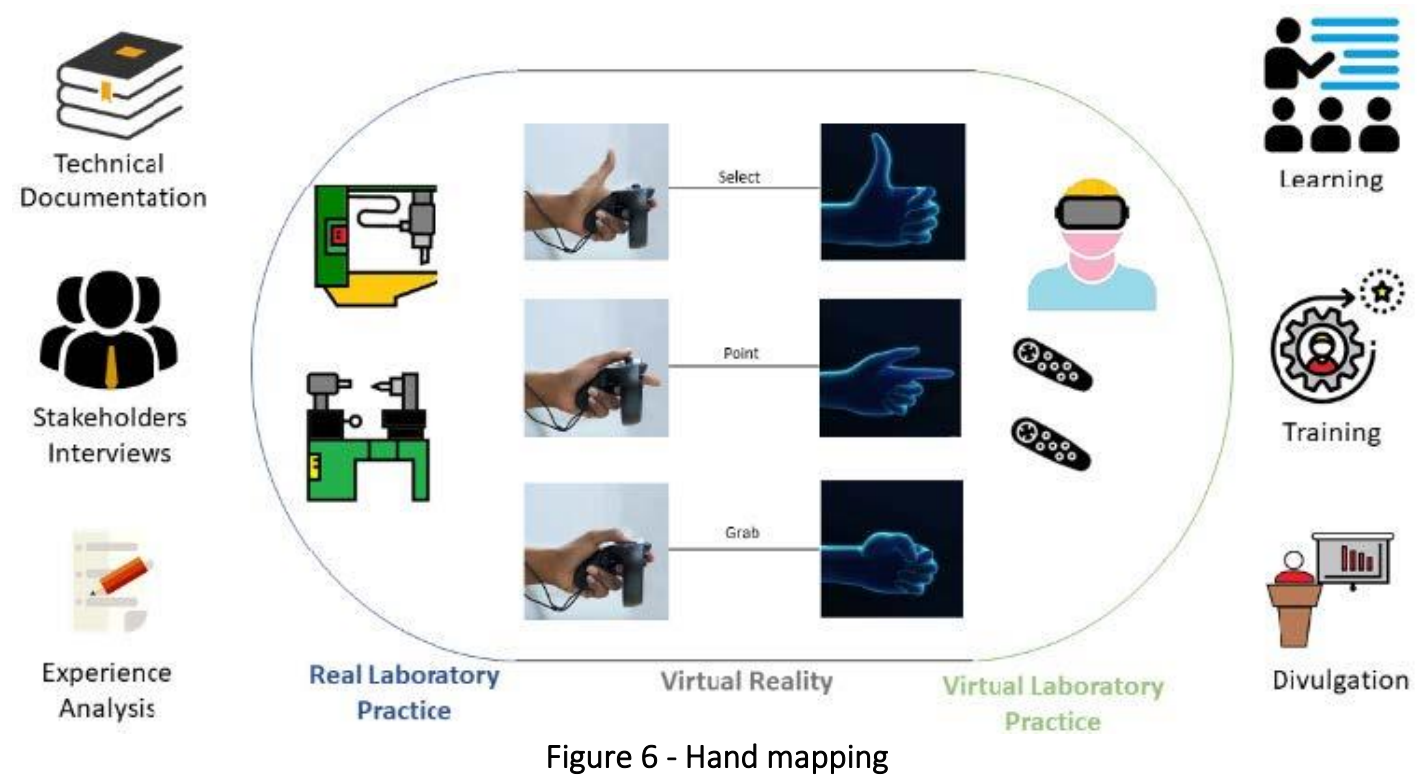




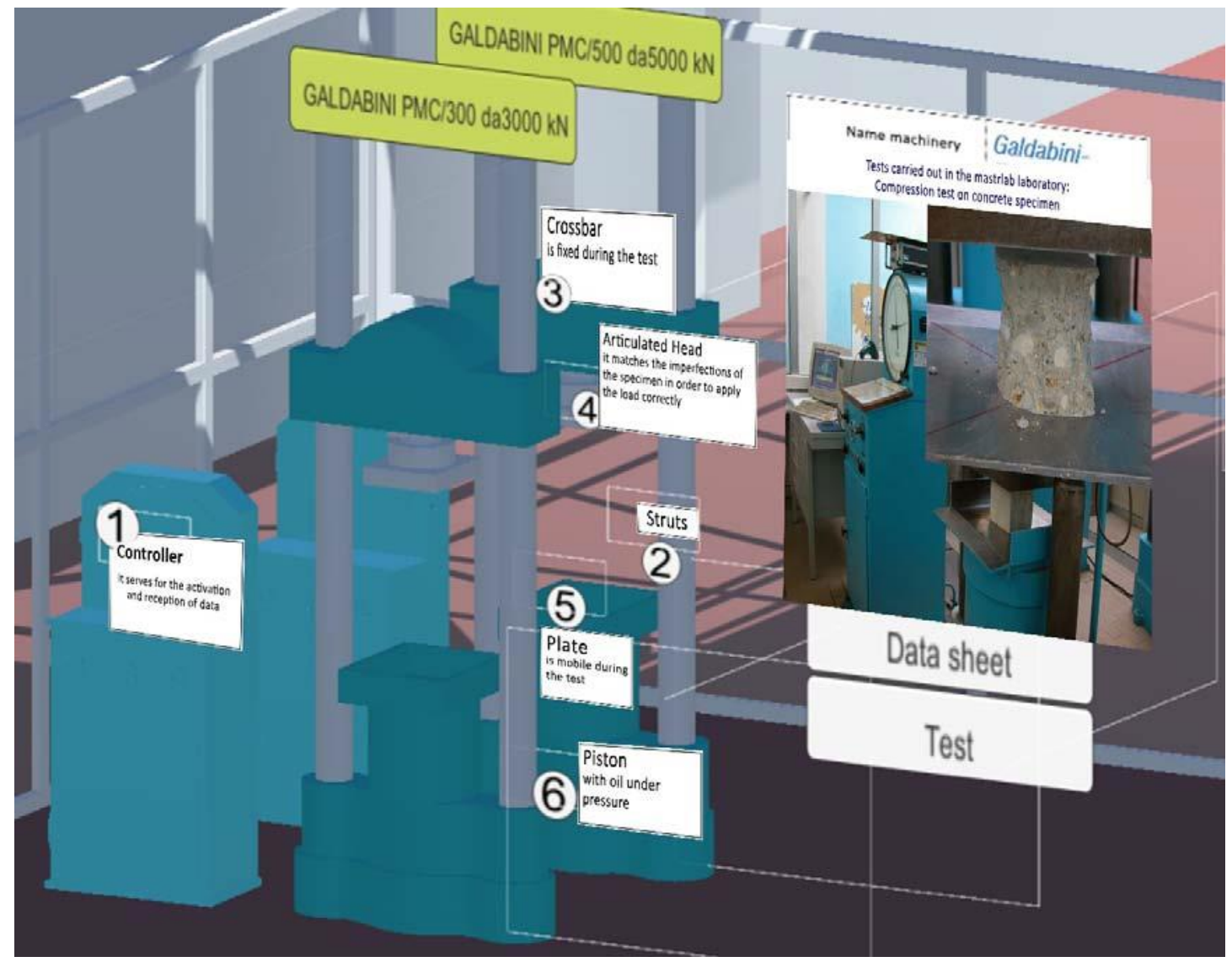

Figure 7 - Laboratory machines

In Fig. 6 it is shown how the hand interaction system has been developed. Starting from the reading of technical documentation and with the support of stakeholders and the analysis of tasks, the hand related movements have been ported in the VR system using the Oculus Rift controller API provided by Oculus. At the end of the process, the real laboratory operations result is translated inside the VR environment to create the virtual laboratory. This result shows its main potentialities in learning laboratory-related subjects, training operators on new technologies and divulgation of scientific researches to a wide variety of users.

As reported in the official documentation, the Oculus Rift touch controller allows replicating some virtual gestures starting from real ones by using touch sensors installed in the joystick, trigger and grip buttons. Once the user became familiar with the system, the use of this type of controller led to a cleaner and intuitive experience. Through the movement's logic controller, the information detected by touch controller sensors has been used to improve experience and to increase immersivity. Three kinds of gesture have been implemented:

- Point: It's used to point an option or an object on screen

- Select: It's used to interact with the virtual environment

- Grab: It's used to grab the objects

The virtual experimentation experience consists of the implementation of series of laboratory tasks. It depends on the Machining Logic that shares data with the Machining and materials database, containing the necessary information that can be classified in two categories:

- Machining Data: Data related to processes, list of materials

- Machines Data: Data related to machines 
The link between this data and the 3D model is guaranteed by the use of unique TAG for every design.

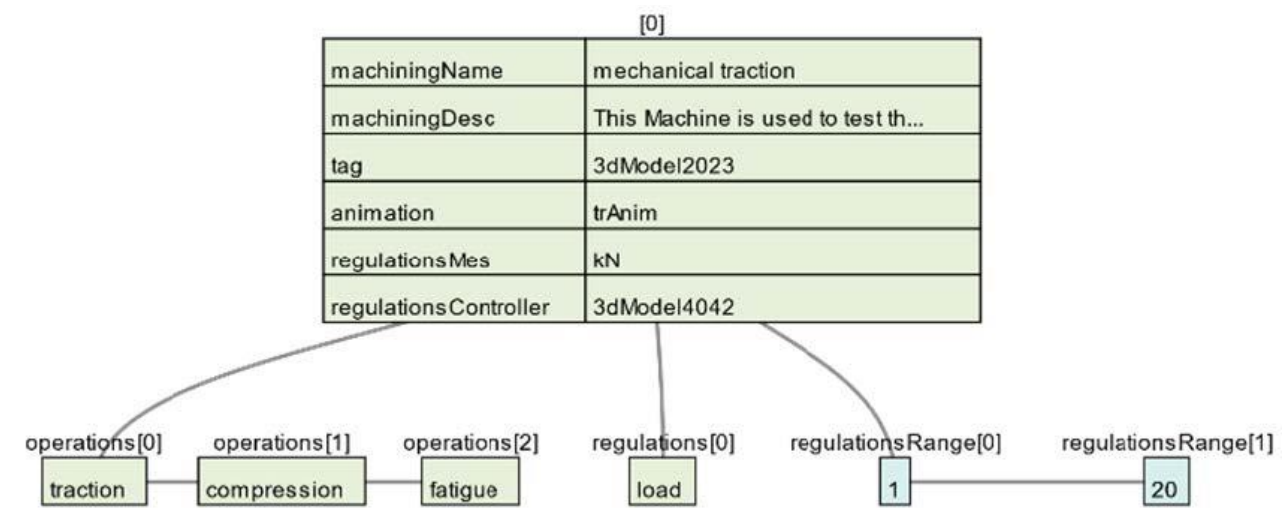

Figure 8 - Item of machining and materials database

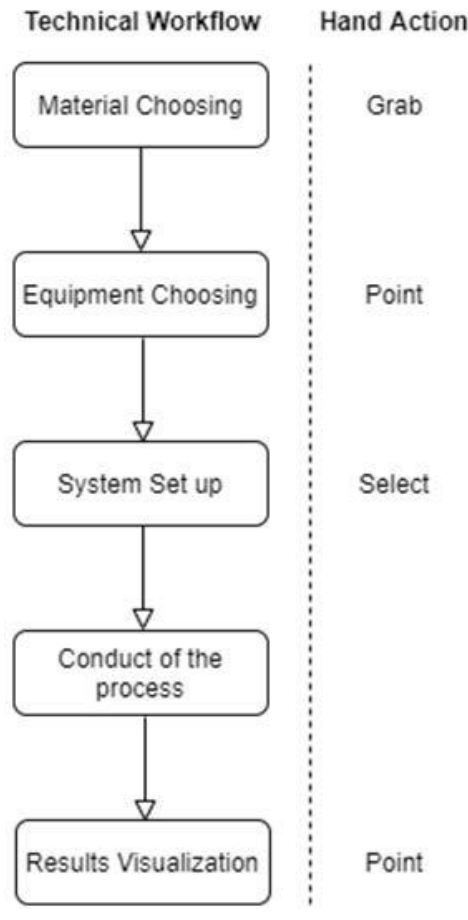

Figure 9 - General workflow for system activities
Fig. 8 represents one item of the machining and materials database for a UTM (Universal Testing Machine). The field machiningDesc contains a brief description about the machine and it can be visualized by clicking a button on the 3D Model of the machine. The link between the data and the model is defined through the string tag. Animation field is necessary to link the animation to the model.

The other parameters are technical parameters related to setting range for the processing, the operation that the machine can perform and the regulationsController that is a link to the 3D model of the machine computer where the user can interact and change the parameters.

In a typical session, the user starts from choosing the material for the practice. Different materials preserve different properties and their choice influences the result of the procedure. Next phase is the choice of the machining. At the end of the procedure, the user has to arm the machine and he can visualize the result in term of visual product and in terms of data.

One of the mechanical processing that has been integrated inside the software is the mechanical breakage of the specimen. The process started from the choice of the material. The user must carry the specimen after having collect by using the controller gesture for grab, on the forklift. After that, he can drive the forklift, by starting the engine through virtual button pressure. He can move around the path dedicated to forklift inside the laboratory to bring the piece near to machine. After that he must program the load of the machine. By using simple mechanical calculation, having the property for the specified specimen, the software calculates the theorical effect of the strength application on the specimen.

During the phase of machining, where the machine reproduces animation related on movements for that particular processing, the user can see how the process works and at the end of this, he can see the final product, how the damage for the strength have been spread around the specimen structure. Also, the system creates graph reporting the result of the process in analytical way. 
Every process activates flags to preannounce that the task has been completed. At the end of the experience, participants are asked to take a virtual test. In this task, different questions, based on the activities accomplished, are loading inside through the Quiz Logic component that communicates with questions Database. The Quiz logic Controller is the main actor that creates interface between the backend and the database. It reads all the flag and query the database in order to obtain the associated questions.

The test is based on multiple answers in a number from 2 to 4 . Another parameter is the time used by the user to complete the test. Results are saved inside a local database, containing timestamp, time for completion and \% of success as reported in Fig. 13.

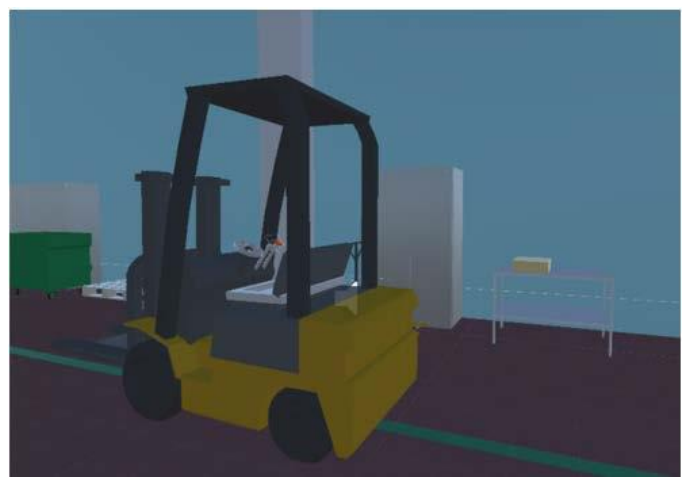

Figure 10 - 3D model of the forklift

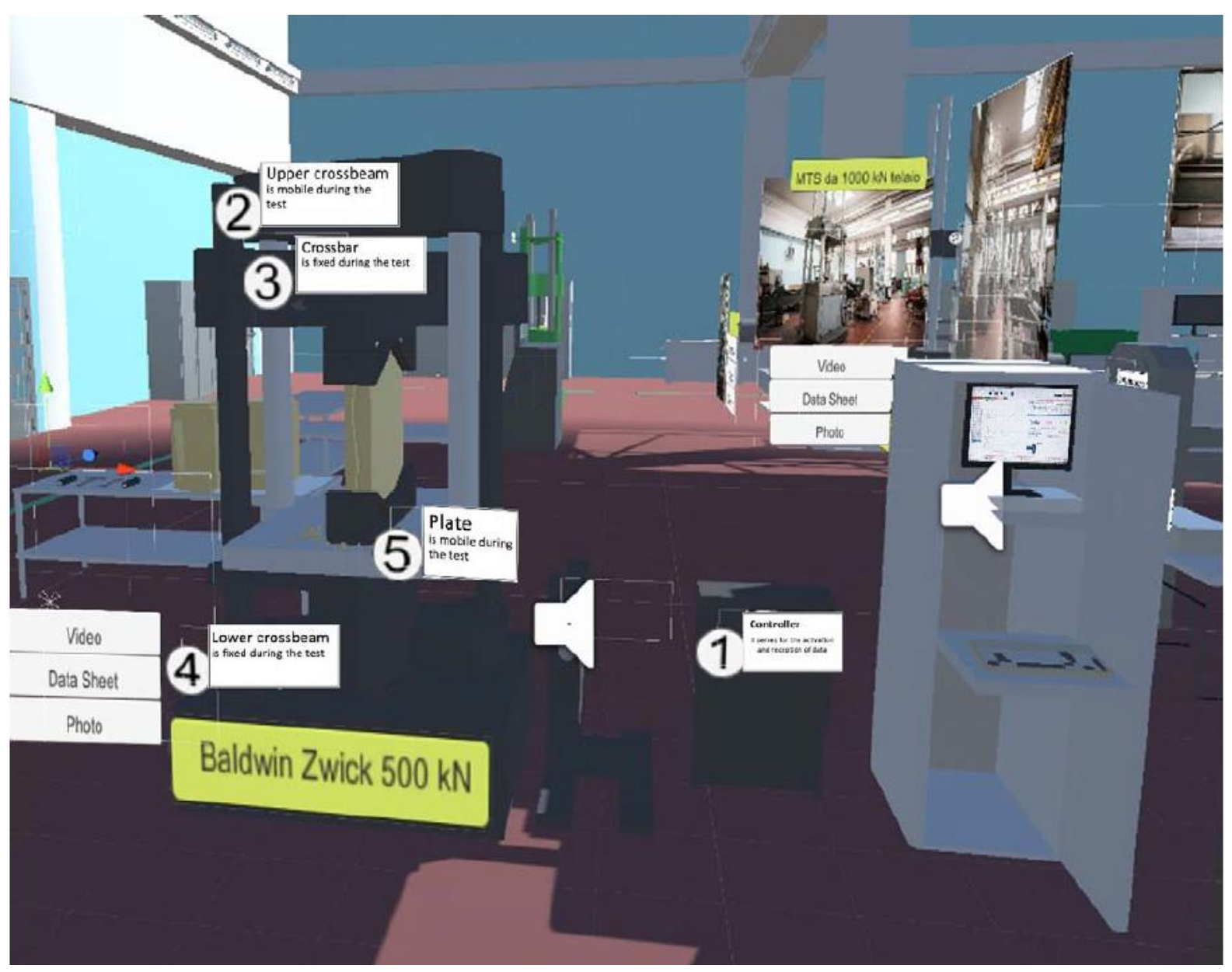

Figure 11 - 3D model of the equipment 


\section{Results}

As a research laboratory, we have proposed the software to different stakeholders in order to evaluate its effectiveness in the aspect of: Divulgation, Practical Impact and how this technology could present the laboratory outside polytechnic walls. "Italian Tech Week (ITW) is a non-profit project promoted by the Turin Chamber of Commerce, Club degli Investitori, Compagnia di Sanpaolo, Fondazione CRT, Fondazione LINKS, OGR, Politecnico di Torino, School of Entrepreneurship and Innovation (SEI), Torino Social Impact, Unione Industriale di Torino and University of Turin and aims to strengthen the integration of the territorial ecosystem of innovation, while offering opportunities for discussion and reflection at national and European level. During these events, MASTRLab VR has been presented to users belonging to different work areas, various ethnic groups and with different cultural backgrounds" [11].

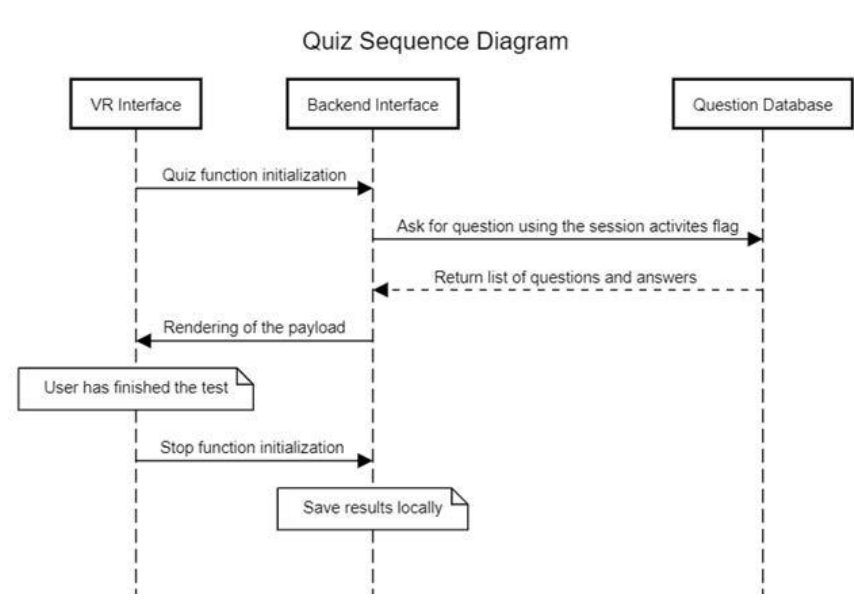

Figure 13 - Sequence diagram for quiz logic
[0]

\begin{tabular}{|l|l|}
\hline Timestamp & $2019-12-23 T 18: 25: 43.511 Z$ \\
\hline TimeTo & 50 \\
\hline Score & 70 \\
\hline
\end{tabular}

Figure 12 - Item of test result

The age distribution is reported in Fig. 14. As visible, the major number of participants had an age from 15- 30 years. In the range 40-60 years, $18.6 \%$ of the total people attended to the event, this value shows a great overture in front of this kind of technology also for adults. Totally the number of participants was 134 , with a mean age of 29.40 years old and a standard deviation of 17 .

First, the level of user experience with virtual reality devices has been evaluated. The results, as reported in Fig. 15, show that whole participants group can be divided in two groups: the first one has already been involved in this kind of experience, while for the second one is the first time.

After these preliminary questions, all participants have been subjected to the trial of the technology. At the end of the test, four main aspects have been evaluated:

- Virtual involvement

- Divulgation

- Learning Strategy

- Quiz evaluation

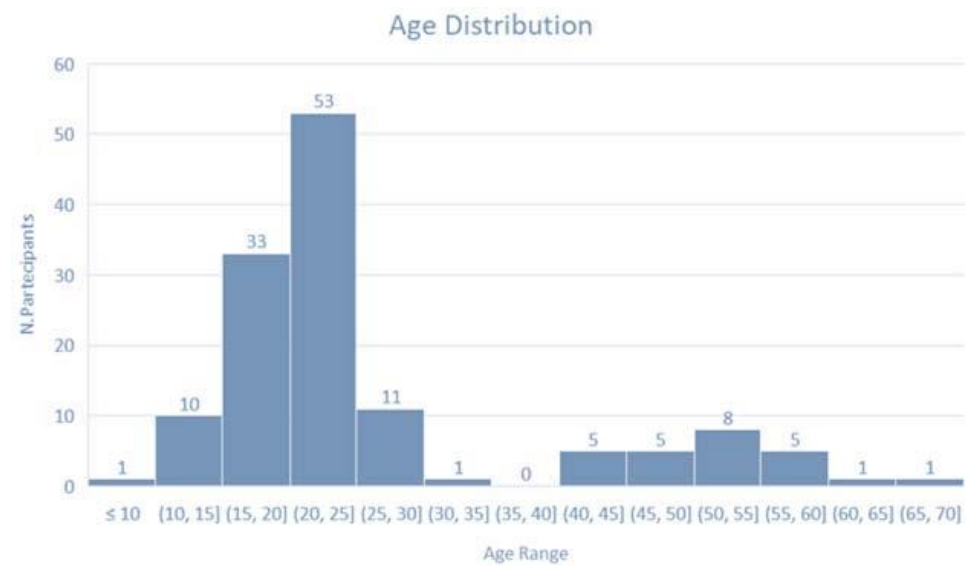

Figure 14 - Participants' age distribution 
The first four indicators have been measured with a survey. Every question of the survey presents answer in a scale of 4 values: "Not at all satisfying", "Poor satisfying", "Enough satisfying" and "Very satisfying".

With the Virtual Involvement parameter the appealing amount of the experience has been evaluated.

How much appealing the experience

was?

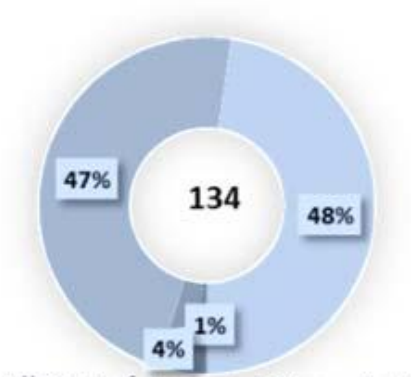

Not At All Satisfying $=$ Poor Satisfying

Enough Satisfying Very Satisfying

Figure 15 - Liking chart, evaluating the appealing of the application.

As shown in Fig. 16, 48\% of visitors was very satisfied of the experience, while $47 \%$ was enough satisfied. This led to $95 \%$ of positive ratings. Among the negative ones, just $4 \%$ was poor satisfied and only the $1 \%$ judged the experience not at all useful.

\section{Do you think that this application could be useful for the divulgation of lab activities?}

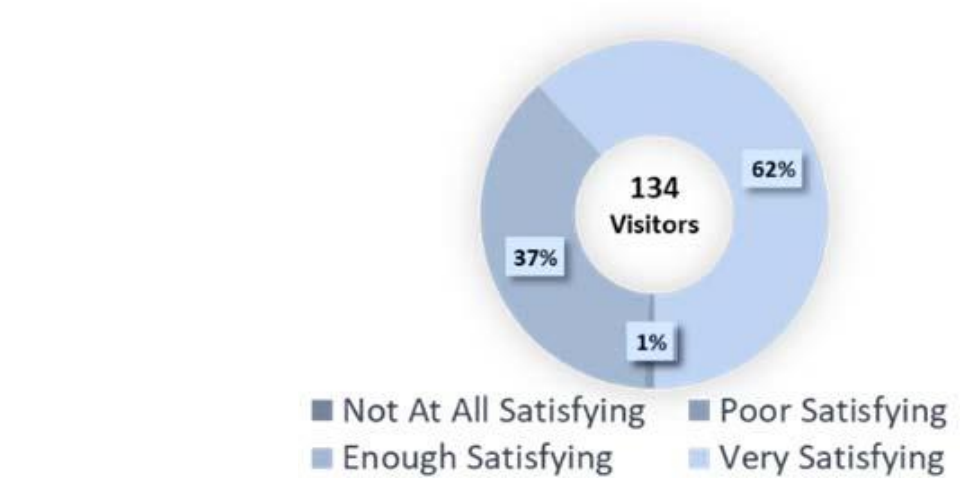

Figure 16 - Participants' opinion on the propensity to disclosure the laboratory activities

The Divulgation indicator shows how the experience is considered as a divulgation tool for the diffusion of highly specialized activities made in MASTRLab. $98 \%$ of participants conveyed in the use of the software for the diffusion of the operations conducted inside the lab.

The third parameter under survey was the evaluation of the learning strategy. Also, in this case, the percentage of satisfaction is very high. This represents how the software is really appreciated from the selected audience. 


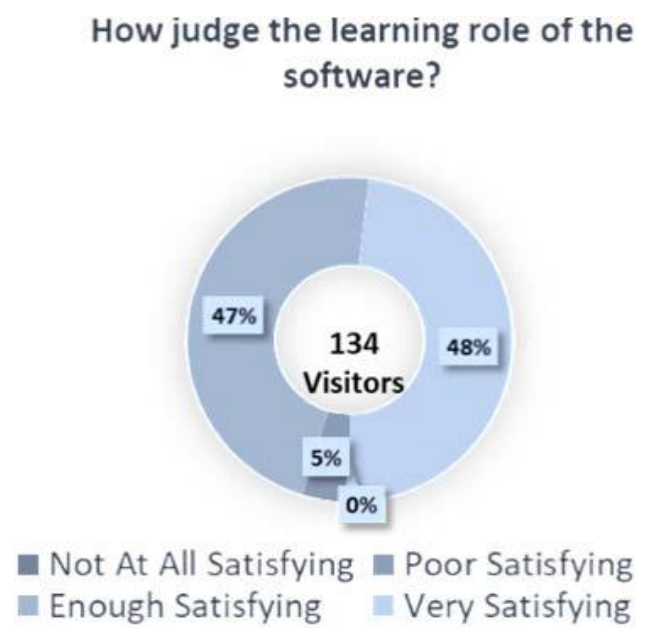

Figure 17 - Participants opinion on the learning system proposed by the framework.

To formalize the learning imprinting that this software can bring to users, every participant has done the final quiz for the selected machining process.

Table 2 - Quiz results for 134 attendees

\begin{tabular}{|l|c|c|c|c|c|}
\hline Number of participants & 7 & 17 & 31 & 20 & 59 \\
\hline Quiz score & $0-20 \%$ & $20-50 \%$ & $50-70 \%$ & $70-90 \%$ & $90-100 \%$ \\
\hline Mean time (s) & 360 & 420 & 330 & 500 & 382 \\
\hline
\end{tabular}

With respect to total number of participants, $79.06 \%$ of them totalize a score from $90 \%$ to $100 \%$ in 382 seconds. This is a great percentage of success, considering furthermore establishing a boundary to pass the test equal to $50 \%$ the $82 \%$ of participants passed the test, with respect to $18 \%$ that has been instead rejected.

\section{Conclusion}

The enormous potential of this MastrLAB-VR application is the possibility to make training in an effective, fast, cheap and safe way, allowing to reduce the costs of material for the exercises and ensuring a safe training without exposing students or objects of their experience to danger or damage. It is the first VR laboratory of the Department and is aimed at different users: students, professors, laboratory technicians who need to operate in total safety and access from anywhere. The MastrLABVR allows simulating in an absolutely realistic and safe way the activities of traditional machinery. The laboratory activity is an important element to establish continuity between theoretical activity and practical experimentation. This system is, therefore, aimed at learning innovative tools in order to enhance the results of laboratory activities. The virtual laboratory is designed to simulate practical exercises with the use of machinery for the students of Building and Civil Engineering courses: tensile tests, universal tests, dynamic tests, relaxation tests, steel qualification tests, compression tests, multiaxial tests, fatigue tests, resilience tests on elements under environmental conditions or at characterizing temperatures, hardness control tests. 
The university must always be sensible to continuous innovation, to progress and technological renewal. This is why the great opportunity to use VR technology in the educational field allows considerable advantages, described above, and creates immense opportunities - from student recruitment [12] to the learning process of real activities [13]. The development of applications in VR will require professional skills so the new generation of VR specialists such as graphic designers, programmers and engineers must be trained first of all to provide solutions that are not only technically perfect but will take into account all the needs. We have seen how, if designed correctly, virtual training has a number of advantages: it is fun, effective and it allows you to keep what you have learned for a long time. These innovative teaching methods, with the aim of strengthening the teaching offer and learning processes, are aimed at a greater understanding of the individual learning processes of the group dynamics that are triggered in a classroom. Specially with the increasing number of digital technologies in the construction industry such as use of Al to predict compressive strength of concrete [15-18], and other environmental automated systems [19-29], the need for VR integration becomes more obvious than ever.

\section{References}

[1] Cornali, F. (2012). Effectiveness and Efficiency of Educational Measures: Evaluation Practices, Indicators and Rhetoric. Sociology Mind, 2, 255-260.

[2] Fondir.it Guida ai principali metodi per innovare la formazione Accessed 10 January, 2020. Retrieved from http://www.fondir.it/sites/default/files/learningplan/guida.pdf

[3] Tony DeMarinis, Lynne Calligaro, Cary Harr, Joe Mariani, Real learning in a virtual world, article by Deloitte, August 2018

[4] Idc.com European Spending on Augmented and Virtual Reality Expected to Increase Ten Times from 2018 to 2022, According to IDC Accessed 12 January 2020, Retrieved from https://www.idc.com/getdoc.jsp?containerld=prCEMA44661219B

[5] K. Abrosimova, 5 ways virtual reality will change education. September 2015 (Online). Available:http://www.hypergridbusiness.com/2014/09/5-ways-virtualreality-will-changeeducation/.

[6] Dimiter Velev and Plamena Zlateva, Virtual Reality Challenges in Education and Training International Journal of Learning and Teaching Vol. 3, No. 1, March 2017

[7] https://www.virtualrealityinnovation.eu/ virtual reality innovation Accessed 13 January, 2020. Retrieved from https://www.virtualrealityinnovation.eu/wpcontent/uploads/2019/02/Deliverable-WP3.pdf

[8] C.M. Eastman, P. Teicholz, R. Sacks, K. Liston, BIM Handbook: A Guide to Building Information Modeling for Owners, Managers, Architects, Engineers, Contractors, and Fabricators, Hoboken,NJ: John Wiley and Sons, 2008.

[9] Unity Technologies. Getting started with VR development in Unity. Accessed 14 January, 2020 Retrieved from https://docs.unity3d.com/Manual/VROverview.html

[10] Facebook Technologies LLC. Oculus Touch Controllers. Accessed 15 January 2020 Retrieved from https://developer.oculus.com/documentation/native/pc/dg-input-touch-overview/

[11] Camera Di Commercio Industria Artigianato e Agricoltura di Torino. (n.d.). Italian Tech Week. Accessed 16 January 2020 Retrieved from https://www.to.camcom.it/italian-tech-week

[12] A. Mandelbaum, Colleges begin to take virtual reality seriously. eCampus News. Accessed 18 January, 2020. Retrieved from www.ecampusnews.com/technologies/colleges-virtual-reality941

[13] M. Bountrogianni, Virtual Teaching Tools Take Learning Outside the Classroom. Huffpost Living. Accessed 19 January, 2020. Retrieved from http://www.huffingtonpost.ca/drmariebountrogianni/virtual-classroom-technology_b_8547166.html. 
[14] Smarter With Gartner, Top 10 Strategic Technology Trends for 2019, October 2019, Accessed 11 January, 2020. Retrieved from https://www.gartner.com/smarterwithgartner/gartner-top10-strategic-technology-trends-for-2019

[15] A. Kandiri, F. Sartipi, and M. Kioumarsi, "Predicting Compressive Strength of Concrete Containing Recycled Aggregate Using Modified ANN with Different Optimization Algorithms," Applied Sciences, vol. 11, no. 2, p. 485, 2021, doi: https://doi.org/10.3390/app11020485.

[16] A. Kandiri, E. M. Golafshani, and A. Behnood, "Estimation of the compressive strength of concretes containing ground granulated blast furnace slag using hybridized multi-objective ANN and salp swarm algorithm," Construction and Building Materials, vol. 248, p. 118676, 2020.

[17] A. Kandiri and F. Fotouhi, "Predicting the creep coefficient of green concretes containing ground granulated blast furnace slag using hybridized multi-objective ANN and Salp swarm algorithm," Journal of Construction Materials, vol. 2, no. 2021, pp. 2-1, 2020.

[18] A. Kandiri and F. Fotouhi, "Prediction of the module of elasticity of green concretes containing ground granulated blast furnace slag using hybridized multi-objective ANN and Salp swarm algorithm," Journal of Construction Materials, vol. 2, no. 2021, pp. 2-2, 2020.

[19] F. Sartipi, "Dynamic data processing for building energy consumption," Journal of Construction Materials, vol. 2, no. 2021, pp. 2-4, 2020, doi: https://doi.org/10.36756/JCM.v2.2.4.

[20] A. Todhunter, M. Crowley, M. Gholamisheverini, and F. Sartipi, "Advanced technological implementation of construction and demolition waste recycling," Journal of Construction Materials, vol. 1, no. 1, 2019, doi: https://doi.org/10.36756/JCM.v1.1.3.

[21] F. Sartipi, "Automatic sorting of recycled aggregate using image processing and object detection," Journal of Construction Materials, vol. 1, pp. 3-3, 2020, doi: https://doi.org/10.36756/JCM.v1.2.1.

[22] T. Boulos, F. Sartipi, and K. Khoshaba, "Bibliometric analysis on the status quo of robotics in construction," Journal of Construction Materials, vol. 1, pp. 2-3, 2020.

[23] F. Sartipi, "A brief critical view on the carbon-conditioning of recycled aggregate using pressure chamber," Journal of Construction Materials, vol. 2, pp. 1-4, 2020, doi: https://doi.org/10.36756/JCM.v2.1.4.

[24] F. Sartipi and A. Sartipi, "Brief review on advancements in construction additive manufacturing," Journal of Construction Materials, vol. 1, pp. 2-4, 2020, doi: https://doi.org/10.36756/JCM.v1.2.4

[25] A. Gharizadeh, F. Sartipi, E. Ayoubi, and A. Severino, "The chemical reactor design configuration of $\mathrm{CO} 2$ concrete green solution," Journal of Construction Materials, vol. 1, pp. 2-5, 2020, doi: https://doi.org/10.36756/JCM.v1.2.5.

[26] F. Sartipi, "Diffusion of Innovation Theory in the Realm of Environmental Construction," Journal of Construction Materials, vol. 1, pp. 4-2, 2020, doi: https://doi.org/10.36756/JCM.v1.3.2.

[27] F. Sartipi, "Influence of $5 \mathrm{G}$ and IoT in construction and demolition waste recycling-conceptual smart city design," Journal of Construction Materials, vol. 1, pp. 4-1, 2020, doi: https://doi.org/10.36756/JCM.v1.4.1.

[28] F. Sartipi, "Organizational structure of construction entities based on the cooperative game theory," Journal of Construction Materials, vol. 1, no. 2, 2020, doi: https://doi.org/10.36756/JCM.v1.3.3

[29] F. Sartipi, K. Palaskar, A. Ergin, and U. Rajakaruna, "Viable construction technology for habitation on Mars: Fused Deposition Modelling," Journal of Construction Materials, vol. 1, no. 2, 2020. 